\title{
Managed Care and Access to Substance Abuse Treatment Services
}

\author{
Jeffrey A. Alexander, PhD \\ Tammie A. Nahra, PhD \\ John R. C. Wheeler, PhD
}

\begin{abstract}
Using nationally representative data from 1995 and 2000, this study examined how managed care penetration and other organizational characteristics were related to accessibility to outpatient substance abuse treatment. At an organizational level, access was measured as the percentage of clients unable to pay for services; the percentage of clients receiving a reduced fee; and the percentage of clients with shortened treatment because of their inability to pay. Treatment units with both relatively low and relatively high managed care penetration were more likely to support access to care; these units provided care to higher percentages of clients unable to pay and were less likely to shorten treatment because of client inability to pay. Treatment units with midrange managed care penetration were least likely to support access to care. The complexity of managing in an environment of conflicting incentives may reduce the organization's ability to serve those with limited financial means.
\end{abstract}

As managed care organizations promote the use of gatekeepers, specialized utilization review, and outpatient over inpatient care, concerns have been raised about how managed care has altered the quality of and access to behavioral treatment services. ${ }^{1-3}$ On the one hand, advocates claim that managed care holds the promise of increasing access and curbing sharply escalating costs by curtailing unnecessary utilization, discouraging ineffective treatment practices, and providing incentives for increased operating efficiency. ${ }^{4}$ However, critics argue that behavioral managed care reduces access to and effectiveness of care both by potentially crowding out those clients who are unable to pay for treatment and by reducing desirable levels of care in the name of efficiency. ${ }^{1-3,5,6}$ Although such concerns have been expressed most often in public policy forums, there is little empirical evidence from national samples of substance abuse treatment providers that might guide policy-makers in these debates. Further, the sharply partisan character of these discussions has deflected attention from the possibility that managed care may, under different conditions, lead to different outcomes with respect to access and level of treatment.

Address Correspondence and reprint request to Jeffrey A. Alexander, PhD, Richard Carl Jelinek Professor of Health Management and Policy, Department of Health Management and Policy, School of Public Health, University of Michigan, 109 S. Observatory St., M3507 SPH II, Ann Arbor, MI 48109-2029. Telephone: (734) 936-1194, fax: (734) 764-4338, e-mail: jalexand@umich.edu.

Tammie A. Nahra, PhD, is Project Manager in Department of Health Management and Policy at University of Michigan, Ann Arbor, Michigan.

John R.C. Wheeler. PhD, is Professor in Department of Health Management and Policy in School of Public Health at University of Michigan, Ann Arbor, Michigan.

Journal of Behavioral Health Services \& Research, 2003, 30(2), 161-175. (C) 2003 National Council for Community Behavioral Healthcare. 
The goals of this study are to evaluate how managed care affects access to outpatient substance abuse treatment (OSAT) and to evaluate how managed care affects the level of substance abuse treatment. Using a nationally representative sample of OSAT units, this research examines the relationship between managed care and 3 important measures of patient access and treatment levels. Treatment access is conceptualized as the willingness of a unit to remove or ease financial barriers to treatment and is measured using 2 dependent variables: (1) the percentage of clients treated by the OSAT who are unable to pay for their treatment and (2) the percentage of clients for which the OSAT charges reduced fees. Level of treatment is conceptualized as the extent to which a unit will continue to provide care, regardless of a clients' financial situation, and is measured as (3) the percentage of clients receiving shortened treatment because of client inability to pay. Two research questions are explored:

1. Is managed care penetration in OSAT units associated with access to and level of treatment provided in these units?

2. Is the relationship between managed care and access and level of treatment monotonic or, alternatively, does this relationship vary across levels of managed care penetration?

\section{Managed Care and Drug Abuse Treatment}

Outpatient substance abuse treatment units represent a central component of the drug abuse delivery system, accounting for nearly $70 \%$ of those in treatment. ${ }^{7}$ Managed care firms often prefer outpatient treatment services because of lower costs relative to inpatient and residential settings and because outpatient care is often the least restrictive alternative for clients. ${ }^{8,9}$

In 1999, about $47 \%$ of OSAT units were involved in managed care, with, on average, $49 \%$ of their revenues coming from managed care arrangements. ${ }^{10}$ OSAT units are most dependent on private managed care arrangements, which constitute $18 \%$ of revenues, compared with $12 \%$ from Medicaid managed care and $9 \%$ from other public managed care programs.

The most common form of managed care oversight involves limiting the number of visits received by clients. On average, $78 \%$ of OSAT managed care clients are subject to some type of visit limits from the managed care firm. Managed care firms are also involved in the specification of the nature and types of treatment to be reimbursed. On average, managed care firms specify the content of treatment plans for $48 \%$ of managed care clients and require follow-up with clients after discharge for $23 \%$ of all managed care cases. Managed care firms disallowed claims after treatment ended for an average $32 \%$ of managed care clients. ${ }^{11}$ These studies all suggest that managed care varies in its approach to cost and care management and that such variation may occur not only across organizational providers but also within providers as a function of their dependence on managed care.

Most research on managed care has focused on a few large-scale managed care programs and their effects on clients' access to and use of treatment services. For example, one widely cited study examined effects of the Massachusetts statewide managed care system for Medicaid mental health and substance abuse benefits. ${ }^{12}$ A recent review of results from studies of the effects of managed care on behavioral health services suggests that there is evidence of reductions in the use of both inpatient and outpatient treatment. Steenrod et al ${ }^{13(\mathrm{p} 27)}$ conclude that “... the emerging pattern of reductions in access to alcohol and drug abuse services in commercial health plans and public plans for state employees and Medicaid enrollees is disturbing and a clear indicator that much more attention must be directed toward the analysis of substance abuse treatment."

Several problems, however, characterize this research. First, there are few comprehensive studies that focus specifically on managed care activities and their effects in outpatient settings. Hence, there is no clear understanding of how managed care may influence treatment practices. Second, those 
studies that focus on the organizational effects of managed care have included either a small number of case studies or a single state managed care initiative. The findings to date may therefore be biased by the specific attributes of a few managed care programs or a single state Medicaid system. Finally and perhaps most important, the research to date has generally not considered how the effects of managed care on treatment access and level may vary as a function of the providers' dependence on managed care.

Alexander and Lemak ${ }^{14}$ examined treatment unit directors' perceptions of the costs and benefits of managed care. Their results indicate that directors view the impact of managed care more negatively to the extent that a moderate number of their clients (relative to a low or high number) are covered by managed care. The authors suggested that when managed care represents a minor element of the unit's business there is little need to change standard operating practices. As the proportion of managed care business increases, both administrative and clinical conflicts may result between externally imposed requirements and standard operating practices of the unit. Finally, as managed care becomes a dominant source of clients and payment, managed care protocols may be mainstreamed, resulting in fewer perceived conflicts with premanaged care practices. Similarly, VanHorn and colleagues ${ }^{15}$ reported that physicians in the general health care sector changed their clinical practice patterns at threshold levels of managed care. Specifically, managed care as a proportion of a clinician's caseload did not appreciably affect general clinical behavior until it reached a threshold point, after which these practices and behaviors were applied widely across a physician's client base, regardless of whether those clients were actually insured under managed care.

These results suggest that the way in which managed care affects access to and levels of care for substance abuse treatment clients may change over the range of managed care penetration in a unit. In OSAT units such nonlinear effects occur because the treatment requirements and pressures for financial efficiency imposed by managed care may often conflict with preexisting clinical practices and financial incentives. Organizations will attempt to resist the imposition of requirements by managed care on OSAT unit operations to the extent that they can afford to engage in such resistance. However, they must seek a way of accommodating preexisting practices with new ones imposed under managed care as dependence on managed care increases.

Perhaps nowhere are these dynamics more apparent than in the area of access to and care for financially disadvantaged clients. Both critics and proponents of managed care have argued that managed care places increased financial pressure on OSAT units by reimbursing care at lower rates and tying payment to more limited treatment periods. ${ }^{16}$ These financial incentives force OSAT units to engage in practices that place greater emphasis on financial viability and efficiency. Those clients who are unable to pay because they lack insurance coverage, or cannot pay for services out of pocket, or cannot pay a price sufficient to cover costs, are a direct financial liability to OSAT units under this scenario.

OSAT units may be likely to reduce or eliminate such financial losses through 3 mechanisms. The first is to reduce access to services by clients who are unable to pay. Second, for those clients who are uninsured or underinsured, the OSAT unit facing managed care pressures may show greater reluctance to reduce fees for services for these groups. Finally, OSAT units may engage in efforts to curtail the quantity (ie, level) of services provided to clients as a way of expending fewer resources per case.

Consistent with the literature described above, this work posits that these practices may assume a nonmonotonic relationship with managed care penetration in the OSAT unit. At low levels of managed care penetration, pressures to increase efficiency are minimal, and access to services by disadvantaged groups may be relatively unaffected. However, at higher levels of managed care penetration, financial pressures on OSAT units increase, and we anticipate greater attempts to reduce access, eliminate financial subsidies, and shorten treatment for nonpaying clients. At very high levels of managed care penetration, however, conflicts between traditional treatment practices and universal access, on the one hand, and pressures by managed care to increase efficiency and financial viability, on the other, 
are reduced. This is so because at very high levels, managed care requirements essentially become synonymous with the standard operating practices of the OSAT unit. These arguments lead to the following hypotheses:

Hypothesis 1: OSAT units with either very low or very high levels of managed care penetration will be more likely to accept clients who are unable to pay relative to OSAT units with midrange levels of managed care penetration.

Hypothesis 2: OSAT units with either very low or very high levels of managed care penetration will be more likely to offer clients reduced fees for services rendered relative to OSAT units with midrange levels of managed care penetration.

Hypothesis 3: OSAT units with either very low or very high levels of managed care penetration will be less likely to shorten the duration of treatment relative to OSAT units with midrange levels of managed care penetration.

\section{Methods}

\section{Sample and data collection}

This study uses data from 2 nationally representative samples of outpatient substance abuse treatment (OSAT) units surveyed in 1995 and 1999/2000 as part of the National Drug Abuse Treatment System Survey (NDATSS). The NDATSS is a longitudinal program of research into the organizational structure, operating characteristics, and treatment modalities of such units in the United States. ${ }^{11}$ In the NDATSS, an OSAT unit is formally defined as a physical facility with resources dedicated primarily (more than 50\%) to treating individuals with substance abuse problems (including alcohol and other drugs) on a nonresidential basis. The sample was specifically designed to represent the wide variety of organizations that comprise the nation's complex outpatient treatment system.

Details of the study design and methods used in the NDATSS have been described elsewhere. ${ }^{17.18}$ Briefly, the NDATSS uses a mixed panel design, which combines elements from panel and crosssectional design formats. Data are collected from the same national sample of outpatient drug abuse treatment units, which have been sampled and screened as part of prior waves of the study. These panel units are combined with a new group of randomly selected OSAT units to insure that the sample remains nationally representative. The new units are selected for participation from a sampling frame of the most complete list of the nation's outpatient substance abuse treatment units, compiled by Institute for Social Research at the University of Michigan. In the 1995 wave, the sample was stratified by control status, treatment modality (methadone or non-methadone), and organizational affiliation. The 1999/2000 wave sample was stratified by treatment modality (methadone or nonmethadone). Except as noted, variables from the NDATSS for both the 1995 and the 1999/2000 waves of data were combined as a panel and cross-sectional data file.

After screening and nonresponse, 618 organizations completed interviews in the 1995 wave, and 745 organizations completed interviews in the 1999/2000 wave, with response rates of $88 \%$ and $89 \%$, respectively. Several steps were followed to produce reliable and valid telephone survey data, including two pretests, elaborate interviewer training, extensive checks for consistency within and between sections of the survey instrument, and, when necessary, recontacts with respondents. ${ }^{19}$

The director and clinical supervisor of each participating OSAT unit were asked to complete telephone interviews. Directors provided information concerning the unit's control status, environment, finances, parent organizations, and managed care arrangements. Clinical supervisors provided information about staff, clients, treatment practices, and services provided. After the data were collected, extensive reliability checks were performed within each survey. Results were also 
compared between surveys further to confirm validity. These checks revealed very high levels of consistency in the NDATSS data. ${ }^{16,20,21}$

\section{Measures}

Table 1 displays descriptions and weighted descriptive statistics for the dependent and independent variables, which are described below.

\section{Dependent variables}

This research considers 3 mechanisms that units may employ as means to reduce or eliminate financial losses and increase financial efficiency. These mechanisms potentially improve financial viability of the treatment unit by controlling initial or continued access to care.

\section{Table 1}

Descriptive statistics $(n=1092)$

\begin{tabular}{|c|c|c|}
\hline & Mean & $\begin{array}{l}\text { Standard } \\
\text { deviation }\end{array}$ \\
\hline \multicolumn{3}{|l|}{ Dependent variables } \\
\hline \multicolumn{3}{|l|}{ Access to treatment } \\
\hline$\%$ Clients unable to pay for treatment & 24.41 & 30.86 \\
\hline$\%$ Clients paying reduced fee for treatment & 41.41 & 38.72 \\
\hline \multicolumn{3}{|l|}{ Level of treatmen } \\
\hline$\%$ Clients receiving shortened treatment because of client inability to pay & 1.87 & 7.33 \\
\hline \multicolumn{3}{|l|}{ Independent variables } \\
\hline \multicolumn{3}{|l|}{ Managed care penetration } \\
\hline$\%$ Clients & 17.34 & 28.83 \\
\hline \multicolumn{3}{|l|}{ Treatment unit affiliation } \\
\hline Hospital affiliation & 0.16 & 0.36 \\
\hline Mental health center affiliation & 0.21 & 0.40 \\
\hline Freestanding unit & 0.29 & 0.46 \\
\hline Other affiliation (referent category) & 0.34 & 0.49 \\
\hline \multicolumn{3}{|l|}{ Treatment unit ownership } \\
\hline Public & 0.28 & 0.41 \\
\hline Private not-for-profit & 0.53 & 0.49 \\
\hline Private for-profit (referent category) & 0.19 & 0.39 \\
\hline \multicolumn{3}{|l|}{ Available treatment modality } \\
\hline Methadone $(1=$ unit provides methadone treatment $)$ & 0.15 & 0.35 \\
\hline \multicolumn{3}{|l|}{ Client characteristics } \\
\hline$\%$ Clients African American & 22.05 & 25.44 \\
\hline$\%$ Clients unemployed & 39.71 & 27.65 \\
\hline$\%$ Clients with dual diagnoses & 31.75 & 25.68 \\
\hline$\%$ Clients with prior treatment & 62.05 & 27.09 \\
\hline \multicolumn{3}{|l|}{ Year of data } \\
\hline Year $(1=$ wave $5,1999 / 2000)$ & 0.46 & 0.50 \\
\hline
\end{tabular}

Note: Descriptive statistics are weighted to be nationally representative. 
Access to substance abuse treatment. Two dependent variables describe the accessibility of care within a treatment unit for uninsured or underinsured clients. Percentage of clients unable to pay for treatment reveals the willingness of a unit to care for the indigent substance abuse treatment population. Some units receive funding to supplement the care for these uninsured clients. However, financial pressures of managed care may tighten total available financial resources, forcing limitations in treatment access.

Percentage of clients paying a reduced fee reflects the willingness of a unit to provide services to clients who may be unable to pay full price because they are uninsured or underinsured. Similar to measuring access for clients unable to pay, this measure may reveal how financial capabilities and the mission of the treatment unit respond to managed care participation.

Level of substance abuse treatment. The third dependent variable describes the unit's commitment to a prescribed level of treatment, regardless of their clients' financial standing. Level of treatment is operationalized by measuring the percentage of clients receiving shortened treatment because of client inability to pay. This dependent variable reveals the percentage of clients whose treatment ended prematurely because of financial constraints. This describes an additional method a unit may employ to manage its financial condition in a managed care environment. The ability and commitment of a unit to continue providing "full service" care may be limited if managed care requirements have already stretched resources. ${ }^{a}$

\section{Independent variables}

In this study, managed care is defined as any contractual or noncontractual arrangement that imposes treatment guidelines or restrictions that must be followed in order for the OSAT units to receive payment for services provided. Arrangements may be with public or private managed care programs. Public managed care programs comprise arrangements with Medicaid or other government programs. Private managed care programs include arrangements with health maintenance organizations (HMOs), preferred provider organizations (PPOs), exclusive provider organizations (EPOs), or Employee Assisted Programs (EAPs). ${ }^{10}$ As described earlier, treatment guidelines and requirements may include preauthorization, utilization review, treatment planning, and documentation of outcomes. Managed care penetration for each OSAT unit is measured as the percentage of OSAT clients covered under either a contractual or noncontractual managed care arrangement.

To allow for the possibility that characteristics of the organization might influence access to and level of treatment, we include unit affiliation, ownership status, and treatment modality. Treatment units may be independent or owned or managed by organizations such as hospitals or mental health centers. Such affiliation is measured by 3 dummy variables: hospital, mental health center, or freestanding, with "other" affiliation as the referent category.

Ownership status of the treatment unit is identified as either public, private not-for-profit, or private for-profit. Two dummy variables represent ownership in the model, with private for-profit status as the referent category. Methadone modality is measured by a single dummy variable indicating the unit's participation in this treatment protocol.

Previous research has shown that certain client characteristics are associated with more complex treatment and service needs. Resources may be further stretched by these complex cases, thereby potentially affecting access to and the level of treatment. African American clients with substance abuse disorders often exhibit more complex treatment needs as a result of the social, economic, and health status disadvantages they may experience. ${ }^{22}$ Other client characteristics shown to be associated with increased case severity include clients who are unemployed, ${ }^{23-25}$ clients with mental health problems in addition to their addiction problem-or dual diagnoses, ${ }^{26}$ and clients with some prior substance abuse treatment. ${ }^{27,28}$ 


\section{Analysis strategy}

The unit of analysis was the treatment unit. The data were analyzed in 3 stages. First, descriptive statistics were calculated to examine variation and distribution in the predictors and dependent variables. Univariate statistics were weighted to account for the stratified sampling design. ${ }^{17} \mathrm{Next}$, bivariate correlations were examined to test for multicollinearity; these results did not produce any analytic constraints (Table 2).

The dependent variable measures were represented by proportional variables; therefore, logistic regression models were fit to study the associations between predictor and access variables. Examination of the data suggested that due to the large number of zero values, the dependent variables were overdispersed, ie, variances of the dependent variables were larger than the binomial variables assumed for proportional variables under conventional logistic regression models. Such overdispersion results in invalid statistical inference under standard logistic regression. Specifically, standard errors and associated $P$ values for the regression coefficients obtained under standard logistic regression are artificially small. This results in potentially inappropriate significance for the covariate effects.

In addition to overdispersion of the dependent variables, the research design had a longitudinal component, where most units have observations from 2 data waves (1995 and 1999/2000). Generalized estimating equations (GEE), a multivariate analog of logistic regression, accounted for correlation among repeated measures on the same unit over time and corrected for overdispersion of the dependent variables. An important feature of GEE is that parameter estimates have the same interpretation as parameters estimated using generalized linear models (GLM) for cross-sectional data. GEE accounts for overdispersion and within-unit correlation by correcting the standard errors of the regression coefficient estimates from standard logistic regression, using the sandwich method. ${ }^{29}$ An advantage of the sandwich method is that it does not require the correct specification of the within-unit correlation matrix.

Two models were fit for each dependent variable: model 1 contains all covariates representing potential alternative explanations of the relationship between managed care penetration and access to or level of treatment in OSAT units plus the linear specification of managed care penetration. Model 2 is identical to model 1 except that a quadratic (squared) term was added to represent potential nonlinear associations between managed care and the dependent variable. To determine whether dependent variables vary over time, a variable representing the year in which the data were collected was included in all models. Interaction terms representing the joint effects of year and each of the covariates were tested to determine whether covariant effects vary by year. These interaction terms proved to be insignificant and therefore were not reported.

\section{Results}

Descriptive data presented in Table 1 reveal that an average of $24 \%$ of OSAT unit clients were unable to pay for treatment; another $41 \%$ paid a reduced fee for treatment. Once treatment was initiated, it was less likely that it would be interrupted because of financial constraints. As shown in Table 1 , only $2 \%$ of the clients received shortened treatment because of client inability to pay for continued care. Half of the treatment units participated in some form of managed care. For all units in this sample, an average of $17 \%$ of clients were covered under a managed care arrangement (managed care penetration). When analyzing only those units participating in manage care, $34 \%$ of clients treated in these units were covered under some type of managed care arrangements.

Review of the organizational characteristics indicates that $16 \%$ were affiliated with hospitals, $21 \%$ were affiliated with mental health care centers, $29 \%$ of the units were freestanding, and the remaining $34 \%$ claimed some other type of unit affiliation. Units were predominately private not-for-profit organizations $(53 \%)$ with the remaining units split between public $(28 \%)$ and 


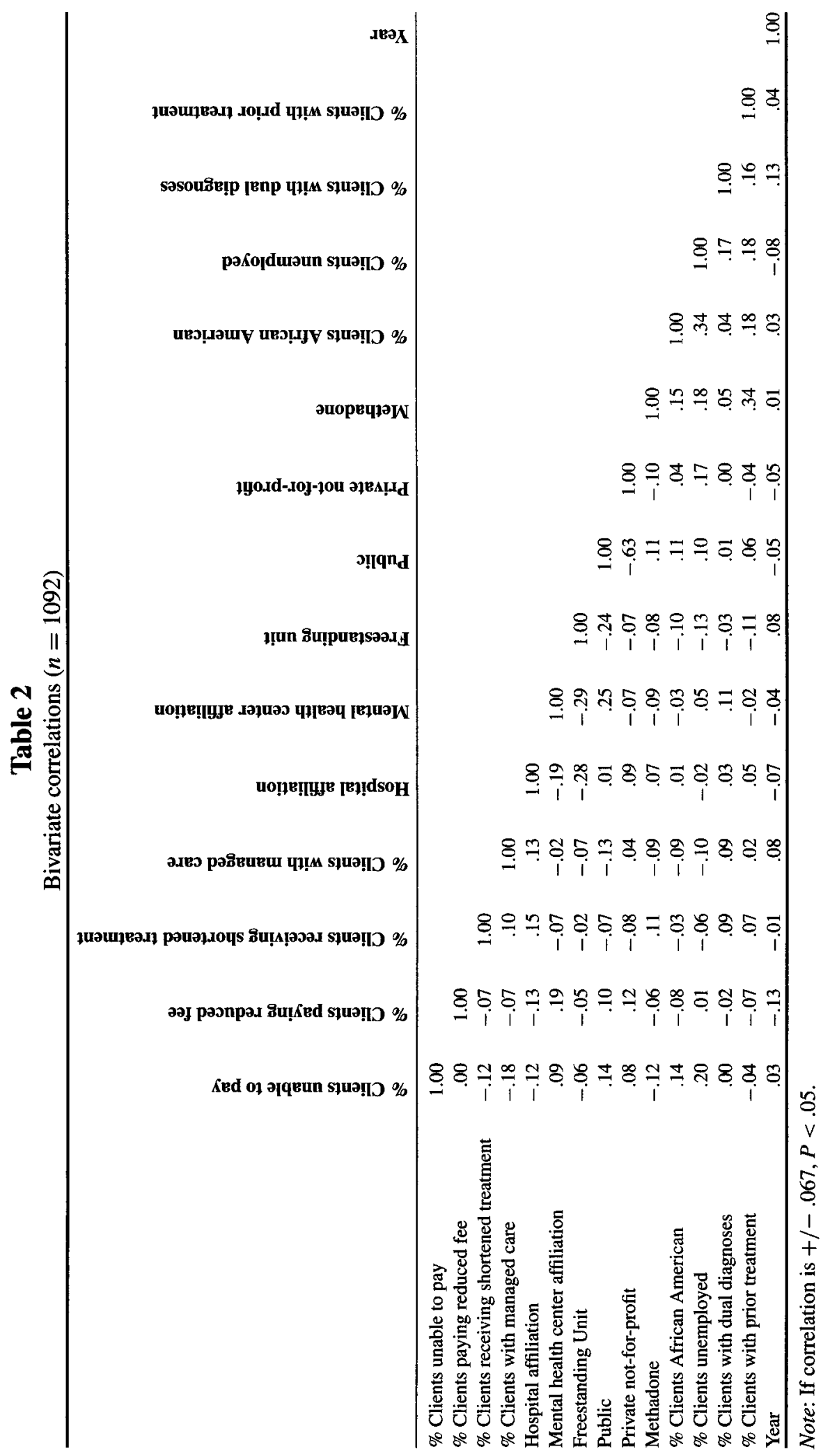


private for-profit (19\%) ownership status. Methadone treatment was available in $15 \%$ of the units.

Client characteristics indicate that $22 \%$ of the clients were African American, $40 \%$ were unemployed, $32 \%$ were dually diagnosed with mental health and substance abuse conditions, and $62 \%$ had prior treatment either at the current treatment unit or elsewhere.

\section{Multivariate results}

Table 3 presents the multivariate GEE results for the 3 dependent variables: percentage of clients unable to pay; percentage of clients paying a reduced fee; and percentage of clients receiving shortened treatment. For each of the 3 dependent variables, 2 regression models are provided. In model 2, a quadratic term was added to model 1 to test the nonmonotonic effect of managed care.

\section{Access to treatment}

\section{Percentage of clients unable to pay}

Model 1 indicates that managed care penetration exercised a significant and negative effect on the percentage of clients unable to pay for care in OSAT units. As the percentage of managed care activity in OSAT increases, units are less likely to treat clients who are unable to pay for their care. In model 2 both the linear term representing managed care penetration and the quadratic (squared) term are significant. These results suggest that the relationship between managed care penetration and percentage of clients unable to pay assumes a U-shaped curve (see Figure 1). OSAT units with low managed care penetration and OSAT units with high managed care penetration are more likely to treat larger numbers of clients unable to pay relative to units with managed care penetration at mid levels of the range. These results are consistent with hypothesis 1.

Other findings indicate that public and private not-for-profit OSAT units are more likely than their private for-profit counterparts to treat larger percentage of clients who are unable to pay. Results also suggest that hospital-based units and freestanding units are more likely than other types of OSAT units to treat large numbers of clients who are unable to pay. Methadone units also are less likely to treat nonpaying clients. None of the variables representing client mix proved to be a significant predictor of percentage of clients unable to pay.

\section{Percentage of clients paying a reduced fee for substance abuse treatment services}

Results reported in model 1 suggest that managed care is not a significant predictor of the percentage of clients paying reduced fee for substance abuse treatment services. For this dependent variable, adding a quadratic term did not improve the explanatory power of managed care on percentage of clients paying reduced fees. Compared to their for-profit counterparts, public and private, not-for-profit OSAT units are more likely to offer clients reduced fees for services rendered. While hospital-based units are less likely to provide such reduced fees, OSAT units affiliated with mental health centers are significantly more likely to provide such a reduced fee program to their clients. Finally, OSAT units with a larger percentage of black clients are less likely to provide reduced fees than comparable units with a smaller percentage of black clients. Collectively, these results suggest that although organizational affiliation, ownership, and client mix exercise significant effects on the percentage of clients receiving reduced fees for services, managed care does not appear to impact this approach to service delivery. 
Table 3

GEE regression results for (model 1) base model and (model 2) nonmonotonic model $(n=1092)$

\begin{tabular}{|c|c|c|c|c|c|c|}
\hline & \multicolumn{4}{|c|}{ Access to treatment } & \multirow{2}{*}{\multicolumn{2}{|c|}{$\begin{array}{c}\text { Level of treatment } \\
\text { Shortened treatment }\end{array}$}} \\
\hline & \multicolumn{2}{|c|}{ Unable to pay } & \multicolumn{2}{|c|}{ Reduced fee } & & \\
\hline & Model 1 & Model 2 & Model 1 & Model 2 & Model 1 & Model 2 \\
\hline \multicolumn{7}{|c|}{$\%$ Clients with managed care } \\
\hline Estimate & $-0.0129 \S$ & $-0.0429 \S$ & 0.0021 & 0.0043 & $0.0134^{\S}$ & $0.0411^{\ddagger}$ \\
\hline SE & 0.0031 & 0.0093 & 0.0030 & 0.0105 & 0.0036 & 0.0154 \\
\hline \multicolumn{7}{|c|}{$\begin{array}{l}\% \text { Clients with managed } \\
\text { care squared }\end{array}$} \\
\hline Estimate & $\ldots$ & $0.0004^{\S}$ & $\ldots$ & 0.0001 & $\ldots$ & $-0.0003^{*}$ \\
\hline SE & $\cdots$ & 0.0001 & $\cdots$ & 0.0001 & $\cdots$ & 0.0002 \\
\hline \multicolumn{7}{|c|}{ Hospital affiliation } \\
\hline Estimate & $-0.8706^{\ddagger}$ & $-0.7848^{\ddagger}$ & $-0.6563^{\dagger}$ & $-0.6625^{\dagger}$ & 0.0879 & 0.0470 \\
\hline SE & 0.2961 & 0.2925 & 0.3016 & 0.2977 & 0.3871 & 0.3877 \\
\hline \multicolumn{7}{|c|}{ Mental health center affiliation } \\
\hline Estimate & -0.2096 & -0.2354 & $0.5698^{\ddagger}$ & $0.5725^{\ddagger}$ & -0.4215 & -0.3815 \\
\hline SE & 0.2172 & 0.2178 & 0.2187 & 0.2189 & 0.5223 & 0.5128 \\
\hline \multicolumn{7}{|c|}{ Freestanding unit } \\
\hline Estimate & -0.3117 & $-0.3662^{*}$ & -0.0187 & -0.0136 & -0.2911 & -0.2502 \\
\hline SE & 0.2218 & 0.2208 & 0.1968 & 0.1969 & 0.3705 & 0.3717 \\
\hline \multicolumn{7}{|l|}{ Public } \\
\hline Estimate & $1.4683^{\S}$ & $1.4264 \S$ & $1.9180^{\S}$ & $1.9239 \S$ & $-1.6336^{\ddagger}$ & -1.4799 \\
\hline SE & 0.3649 & 0.3704 & 0.3362 & 0.3339 & 0.5409 & 0.5377 \\
\hline \multicolumn{7}{|c|}{ Private not-for-profit } \\
\hline Estimate & $1.4596^{\S}$ & $1.4292^{\S}$ & $1.7489 \S$ & $1.7529^{\S}$ & $-1.3067^{\S}$ & $-1.2469^{\S}$ \\
\hline SE & 0.3305 & 0.3379 & 0.2976 & 0.2951 & 0.3728 & 0.3817 \\
\hline \multicolumn{7}{|l|}{ Methadone } \\
\hline Estimate & $-0.4679^{\dagger}$ & $-0.5017^{\dagger}$ & -0.1369 & -0.1341 & $1.4797 \S$ & $1.5097^{\S}$ \\
\hline SE & 0.2458 & 0.2473 & 0.2036 & 0.2031 & 0.3093 & 0.3104 \\
\hline \multicolumn{7}{|c|}{$\%$ Clients African American } \\
\hline Estimate & 0.0043 & 0.0038 & $-0.0108^{\ddagger}$ & $-0.0108^{\ddagger}$ & $-0.0135^{\dagger}$ & $-0.0130^{\dagger}$ \\
\hline SE & 0.0034 & 0.0034 & 0.0035 & 0.0035 & 0.0061 & 0.0062 \\
\hline \multicolumn{7}{|c|}{$\%$ Clients unemployed } \\
\hline Estimate & 0.0033 & 0.0030 & -0.0027 & -0.0027 & -0.0024 & -0.0037 \\
\hline SE & 0.0038 & 0.0039 & 0.0044 & 0.0044 & 0.0067 & 0.0071 \\
\hline \multicolumn{7}{|c|}{ \% Clients with dual diagnoses } \\
\hline Estimate & 0.0037 & 0.0034 & 0.0001 & 0.0001 & $0.0106^{\dagger}$ & $0.0102^{\dagger}$ \\
\hline SE & 0.0037 & 0.0037 & 0.0033 & 0.0033 & 0.0051 & 0.0052 \\
\hline \multicolumn{7}{|c|}{$\%$ Clients with prior treatment } \\
\hline Estimate & -0.0035 & -0.0036 & -0.0002 & -0.0002 & 0.0021 & 0.0033 \\
\hline SE & 0.0031 & 0.0031 & 0.0031 & 0.0030 & 0.0056 & 0.0056 \\
\hline \multicolumn{7}{|l|}{ Year } \\
\hline Estimate & $0.2730^{*}$ & $0.2827^{*}$ & -0.2079 & -0.2076 & -0.2924 & -0.2223 \\
\hline SE & 0.1480 & 0.1489 & 0.1488 & 0.1488 & 0.2688 & 0.2650 \\
\hline \multicolumn{7}{|l|}{ Intercept } \\
\hline Estimate & $-2.2974^{\S}$ & $-2.1244 \S$ & $-1.3183^{\S}$ & $-1.3353^{\S}$ & $-3.7438^{\S}$ & $-4.0316^{\S}$ \\
\hline $\mathrm{SE}$ & 0.4292 & 0.4326 & 0.3412 & 0.3436 & 0.5448 & 0.5115 \\
\hline
\end{tabular}

Note: Pooled data from wave 4 (1995) and wave 5 (1999/2000). The logged odds parameter estimates are from multivariable logistic GEE models with robust standard errors.

${ }^{*} P<.10$.

${ }^{\dagger} P<.05$.

$\ddagger P<.01$.

$\S_{P}<.001$ 


\section{Figure 1}

Relationship between managed care penetration and percentage of clients unable to pay for treatment

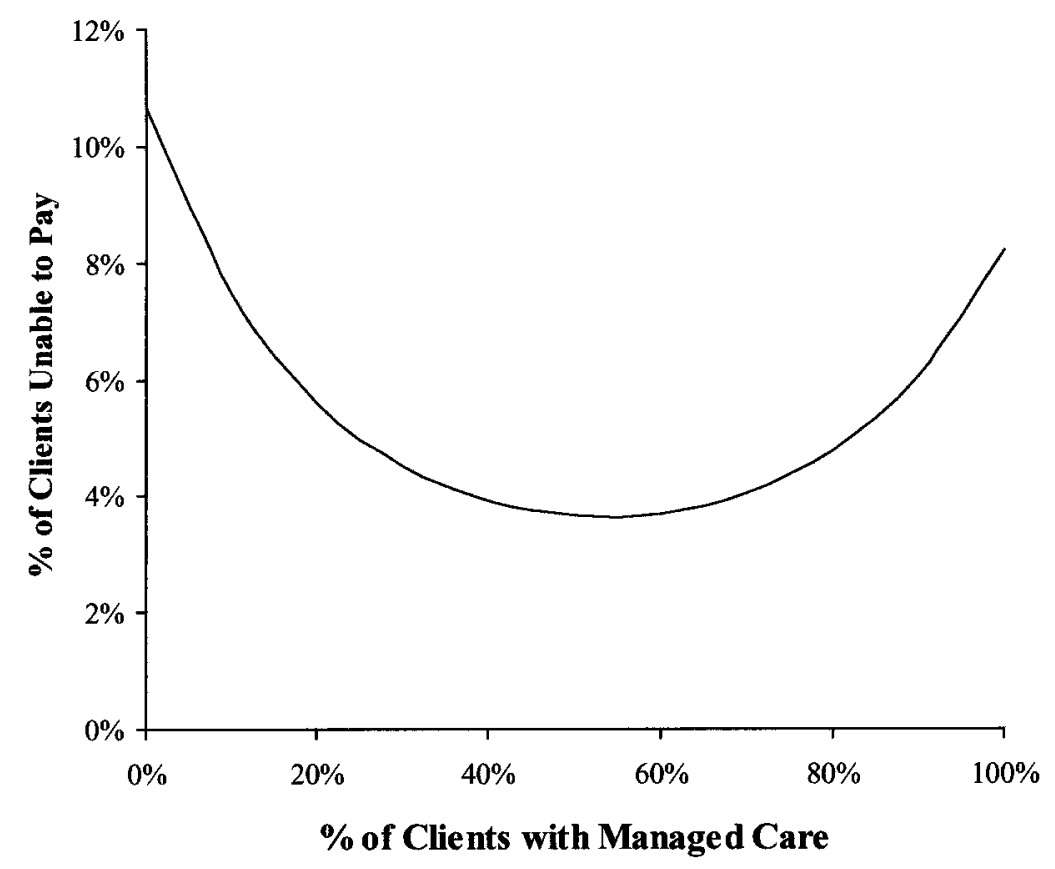

\section{Level of treatment}

\section{Percentage of clients receiving shortened treatment because of client inability to pay}

Model 1 indicates that managed care penetration exhibits a significant and positive association with the percentage of clients receiving shortened treatment because of client inability to pay. When the quadratic expression of managed care penetration is added in model 2, results indicate that the association between the managed care and proportion of clients receiving shortened treatment assumes a curvilinear form in which increasing managed care penetration initially leads to shortened treatment sessions for OSAT clients. However, this relationship plateaus and even declines slightly at $60 \%$ managed care penetration (see Figure 2). This pattern of results is generally consistent with predictions made with hypothesis 3 . Not surprisingly, public and private not-for-profit OSAT units are less likely than their for-profit counterparts to shorten treatment periods for their clients. Similarly, methadone units are much more likely to shorten treatment periods for their clients than are non-methadone units. Among the client mix characteristics, units with a higher percentage of black clients are less likely to reduce treatment periods for their clients, and units with a high percentage of dual diagnosis clients are more likely to reduce treatment periods for their clients.

To further validate the nonlinear effects noted above, categorical variables were substituted for representative range segments of the distribution of managed care penetration. Results (not shown) support the general conclusions previously cited when examining the combination of main effects term and quadratic term of managed care penetration. 
Figure 2

Relationship between managed care penetration and percentage of clients receiving shortened treatment because of their inability to pay

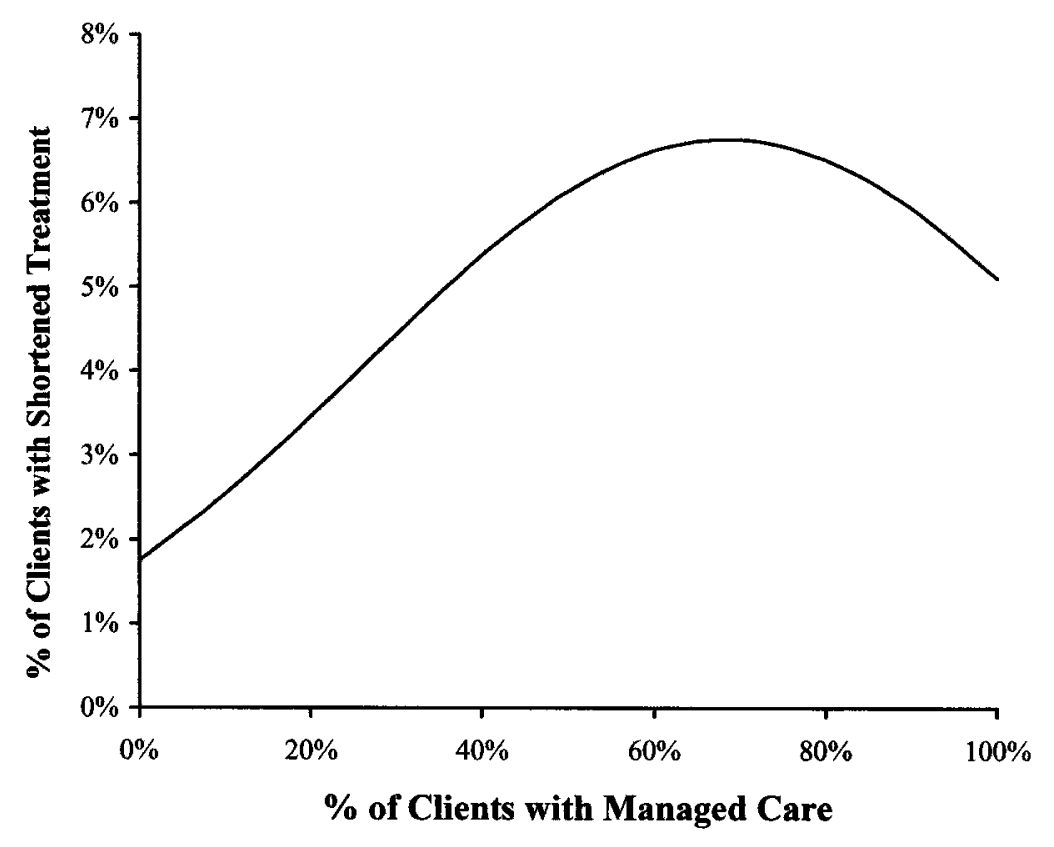

\section{Discussion}

This study has examined how managed care affects the treatment practices and policies of OSAT units. Results indicate that managed care affects both access to and level of treatment provided in such units. However, such effects are shown to vary over the range of values of managed care penetration in OSAT units. One interpretation is that the operational and strategic meaning of reducing access to nonpaying clients, or shortening treatment, may differ substantively depending on the level of dependence of the OSAT unit on managed care. This suggests that managed care should be viewed as much as an important contextual variable providing meaning to organizational strategies and practices as it is a direct determinant of such practices.

The findings indicate that units involved with managed care will employ different strategies to meet financial requirements and that they will use such strategies differently at different levels of managed care penetration. For example, OSAT units characterized by both very low and very high levels of managed care penetration permitted greater access to clients unable to pay compared to OSAT units involved with mid-level managed care penetration. At low levels of managed care penetration, units are less constrained by efficiency requirements of managed care firms and therefore may be more likely to admit greater numbers of patients who are unable to pay for their care. At high levels of managed care penetration, efficiencies may have been achieved, thereby affording OSAT units the ability to accept greater numbers of patients who are unable to pay. Alternatively, units with high managed care penetration may have the added advantage of a stable revenue source and therefore may be in a better position to provide services to those unable to pay. However, at middle range levels of managed care penetration, pressures to achieve efficiencies imposed by managed care firms likely conflict with traditional practices of care to the uninsured. When external 
demands are significant but not dominant, pressures to achieve operating efficiencies may be at their greatest, resulting in lower levels of access to nonpaying clients. These results are consistent with previous studies of the effects of managed care on treatment outcomes for drug abuse treatment clients. $^{14}$

The pattern of relationships between managed care penetration and measures of treatment level is similar to that reported for number of clients unable to pay. Consistent with the hypothesis, as managed care penetration increases, the tendency to provide shortened treatment sessions also increases. However, this effect plateaus and starts to decline when managed care penetration reaches $60 \%$. Units with middle ranges of managed care penetration are most likely to reduce treatment duration for their clients, just as these units are the least likely to serve large numbers of clients who are unable to pay.

\section{Implications for Behavioral Health Services}

For policy-makers, the findings indicate that OSAT units respond differently to managed care as a function of (a) their dependence on managed care (managed care penetration); (b) the strategies and policies by which these organizations attempt to increase efficiency; and (c) the different substantive meanings assumed by access and treatment approaches at different levels of managed care. This is a much more nuanced picture of managed care than has been presented in most previous studies. It suggests that there are clearly contradictory pressures and incentives at work in treatment organizations. On the one hand, substance abuse treatment professionals are dedicated to providing care that would result in the greatest good for their clients, including freedom from substance abuse, maintenance of treatment regimens, and sustained contact with treatment providers and provider organizations. On the other, managed care pressures frequently operate with requirements to reduce costs of care and provide strong incentives to promote operating efficiencies in OSAT delivery. Because such requirements are often at odds with the objectives of treatment professionals, organizations respond in somewhat contradictory ways as a means of balancing them.

It is also important for policy-makers to note that there are clear thresholds at which treatment practices and access to care change in OSAT units exposed to managed care. The likelihood of shortening treatment duration, for example, does not increase linearly with managed care penetration, but levels off at some point. Similarly, access to care for those unable to pay drops with increasing managed care penetration up to a point but then increases. These findings should promote careful consideration by policy-makers of how much managed care is too much, or alternatively, how much managed care is required to see a difference in operating efficiencies within OSAT units.

It is important to note that this study examined changes in access to and level of treatment for all clients in OSAT units, not simply clients covered in managed care. This is an important distinction because it speaks to the adoption and diffusion of practices that may affect a larger population of clients than those specifically targeted by managed care firms. These findings strongly suggest that it is difficult for OSAT units to apply different policies and practices to managed care clients and non-managed care clients. This is particularly true as the levels of managed care penetration rise in OSAT units. As the level of dependence on managed care revenue increases, requirements imposed by managed care and the norms of efficiency are adopted as the standard practices of the organization, not simply as limited responses to gain reimbursement. These findings are consistent with those of Van Horn et al ${ }^{15}$ and others in the general health care sector.

No effects of managed care were found on the tendency of OSAT units to reduce fees for substance abuse clients. Although this practice is common in the sample ( $40 \%$ of all units), high and low managed care penetration OSAT units appear to be equally likely to engage in this practice. However, the strategic and financial importance of this practice may differ between high and low penetration units. For units characterized by low managed care penetration, the reduction of fees may simply be an extension of access for clients who are unable to pay. For units characterized by high managed care 
penetration, however, this strategy is a likely alternative to permitting access to those who are unable to pay. Such an approach may enable the unit to recover some revenue in the face of efficiency pressures without suffering the financial risk associated with treating clients who are unable to pay. Based on the results described above, this practice may be more prevalent in organizations characterized by midrange levels of managed care.

Of course, the overarching policy question is the extent to which constraints on treatment access and delivery imposed by managed care affect the outcomes of treatment. For example, if standards of care are tightly constrained by managed care organizations with the aim of increasing efficiency, are client treatment needs being met and is the effectiveness of care diminished?

\section{Conclusion and Limitations}

These findings should be interpreted with caution. For example, units that limit access to services, or which deliberately scale back on treatment, may be more attractive to managed care firms. In other words, these providers may not react to the pressures of managed care but select into managed care arrangements because their practices are attractive to managed care firms. Although such endogeneity concerns are somewhat obviated by the nonlinear effects of managed care, a longitudinal design or an instrumental variables approach to assessing this possibility is clearly called for in future studies. Second, the study may suffer from some omitted variable bias. The approach used to address this issue was to include as covariates organizational and client characteristics that represent potential alternative explanations to the relationship between managed care and access to and level of treatment. For example, ownership and affiliation exercise consistent effects on the dependent variables.

Although the measure of managed care used in this study was purposely comprehensive, there may be benefit to deconstructing managed care into specific requirements and organizational types. For example, previous research has been criticized on the grounds that managed care represents a broad family of financial incentives and treatment requirements that can vary widely in their effects on providers. Lack of comparability across studies has resulted from inattention to the specific elements of managed care arrangements with which providers must contend and the potential for multiple or even conflicting requirements from different managed care organizations. Accordingly, other measures of managed care should be examined in future studies. These might include whether or not there are stringent visit limits, whether or not OSAT units are specifically rewarded for improving efficiency, or the extent to which requirements are imposed on the actual delivery of services to OSAT clients. Further, future studies might examine whether such requirements vary systematically as a function of MCO type (eg, HMOs, behavioral carve outs, PPOs).

In a related vein, future work should begin to examine the mechanisms by which managed care affects access and level of treatment by exploring its effects on individual provider behavior. We currently know little about how those who are charged with delivering care, individual treatment staff, change their behaviors as a function of the introduction of managed care arrangements in their organizations. To the extent that these staff represent the core production technology of substance abuse treatment organizations, this gap is a serious shortcoming in the ability to design both managed care strategies and organizational structures consistent with desired standards of care for substance abuse clients. Although this study has attempted to open the "black box" of the relationship between managed care and important client treatment practices, there is much more that remains to be done.

\section{Note}

Uncompensated care was evaluated as a financial indicator of accessibility. Typically, uncompensated care is composed of bad debt and charity care. However, extensive testing revealed that participating treatment units did not measure the components of uncompensated care with consistency or reliability. Therefore, use of this variable would not have led to valid conclusions. 


\section{Acknowledgments}

Grants 5RO1-DA03272 and 5RO1-DA087231 from the National Institute of Drug Abuse (NIDA) supported this research. The views expressed here are the authors' and not necessarily those of NIDA. The authors thank Xihong Lin and Thomas A. D'Aunno for their counsel and recommendations.

\section{References}

1. Gondolf E, Coleman K, Roman S. Clinical-based vs. insurance-based recommendations for substance abuse treatment level. Substance Use Misuse. 1996;31(9):1101-1116.

2. Geller JL. Mental health services of the future: managed care, unmanaged care, mismanaged care. Smith College Studies in Social Work. 1996;66(3):223-239.

3. French MT, Dunlap LJ, Galinis BA, et al. Health care reforms and managed care for substance abuse services: findings from eleven case studies. Journal of Public Health Policy. 1996;17(2):181-203.

4. Galanter M, Keller DS, Dermatis H, et al. The impact of managed care on substance abuse treatment: a report of the American Society of Addiction Medicine. Journal of Addictive Diseases. 2000; 19:13-34.

5. Findlay S. Managed behavioral health care in 1999: an industry at a crossroads. Health Affairs. 1999;18(5):116-124

6. Boyle PJ, Callahan D. Managed care and mental health: the ethical issues. Health Affairs. 1995;14(3):7-22.

7. Substance Abuse and Mental Health Services Administration. Cost of Addictive and Mental Disorders and Effectiveness of Treatment. Washington, DC: US Dept of Health and Human Services; 1995.

8. Institute of Medicine. Managing Managed Care: Quality Improvements in Behavioral Health. Washington, DC: National Academy Press; 1997.

9. McLellan AT, Woody GE, Metzer D, et al. Evaluating the effectiveness of addiction treatments: reasonable expectations, appropriate comparisons. In: Egertson JA, Fox DM, Leshner AI, eds. Treating Drug Abusers Effectively. Malden, Mass: Blackwell Publishers Inc; 1997:7-40.

10. Alexander JA, Lemak CH, Campbell CI. Changes in managed care activity in outpatient substance abuse treatment organizations, 19952000. Unpublished manuscript; 2002.

11. National Drug Abuse Treatment System Survey. Respondent Report, 1988-2000. Ann Arbor, Mich: Institute for Social Research, University of Michigan; 2001.

12. Callahan JJ, Shepard DS, Beinecke RH, et al. Mental health/substance abuse treatment in managed care: the Massachusetts Medicaid experience. Health Affairs. 1995;14(3):173-184.

13. Steenrod S, Brisson A, McCarty D, et al. Effects of managed care on programs and practices for the treatment of alcohol and drug dependence. In: Galanter M, ed. Recent Developments in Alcoholism. New York: Plenum Press; 2000.

14. Alexander JA, Lemak CH. Directors' perceptions of the effects of managed care on outpatient substance abuse treatment. Journal of Substance Abuse. 1997;9:1-14.

15. Van Horn RL, Burns LR, Wholey DR. The impact of physician involvement in managed care on efficient use of hospital resources. Medical Care. 1997;35(9):873-889.

16. Lemak CH, Alexander JA. Managed care and outpatient substance abuse treatment intensity. Joumal of Behavioral Health Services \& Research. 2001;28(1):12-29.

17. Adams TK, Heeringa SG. Outpatient Substance Abuse Treatment System Survey: Technical Documentation for OSATSS-5, $1999-2000$. Ann Arbor, Mich: Institute for Social Research, University of Michigan; 2001.

18. Heeringa SG. Outpatient Drug Abuse Treatment Studies: Technical Documentation. Ann Arbor, Mich: Institute for Social Research, University of Michigan; 1996.

19. Groves RM, Biemer PP, Lyberg LE, et al. Telephone Survey Methodology. New York: Wiley; 1988.

20. Friedmann PD, D'Aunno TA, Jin L, et al. Linkage to medical and psychosocial services in outpatient drug abuse treatment organizations: the effect of on-site delivery, external arrangements, case management and transportation on ancillary service utilization. Health Services Research. 2000;35(2):443-465.

21. Friedmann PD, Alexander JA, D'Aunno TA. Organizational correlates of access to primary care and mental health services in drug abuse treatment units. Journal of Substance Abuse Treatment. 1999;16(1):71-80.

22. Seale JP, Muramto ML. Substance abuse among minority populations. Substance Abuse. 1993;20:167-180.

23. Alemi F, Stephens RC, Llorens S, et al. A review of factors affecting treatment outcomes: expected treatment outcome scale. American Journal of Drug and Alcohol Abuse. 1995;21(4):483-509.

24. Ornstein P, Cherapon JA. Demographic variables as predictors of alcoholism treatment outcome. Journal of Studies on Alcohol. $1985 ; 46(5): 425-432$.

25. McLellan AT, Alterman AI, Metzger DS, et al. Similarity of outcome predictors across opiate, cocaine, and alcohol treatments: role of treatment services. Journal of Consulting and Clinical Psychology. 1994;62(6):1141-1158.

26. McLellan AT: Patient characteristics associated with outcome. In: Cooper JR, Altman F, Brown BS, et al, eds. Research on the Treatment of Narcotic Addiction: State of the Art. Rockville, Md: National Institute of Drug Abuse; 1983:500-529.

27. Joe GW, Simpson DD, Sells SB. Treatment process and relapse to opiod use during methadone maintenance. American Journal of drug Alcohol Abuse. 1992;19:124-130.

28. Simpson DD. Effectiveness of drug-treatment: a review of research from field settings. In: Egertson JA, Fox DM, Leshner AI, eds. Treating Drug Abusers Effectively. Malden, Mass: Blackwell Publishers Inc; 1997:41-74.

29. McCullagh P, Nelder JA: Generalized Linear Models. 2nd ed. London: Chapman and Hall; 1989. 